\title{
Maceió é uma Cidade Mítica: o Mito da Origem EM NiSE DA SILVEIRA
}

\author{
Walter Melo ${ }^{1}$ \\ Universidade Federal de São João Del Rei
}

O presente artigo aborda o mito da origem da liberdade em Nise da Silveira a partir de histórias de sua infância, de seu apelido Caralâmpia - inspirador de Graciliano Ramos para compor A Terra dos Meninos Pelados-e de seu nome, retirado dos sonetos de Cláudio Manuel da Costa. As originais contribuições de Nise da Silveira no campo da saúde mental passam a ser vistas pelos grupos que dela se aproximaram como frutos de sua genialidade, encontrando explicações nos relatos autobiográficos de Nise da Silveira, consagrados por seus (per)seguidores. O campo da saúde mental no Brasil abrange dois períodos: o da campanha prómanicomial, de 1829 até as primeiras décadas do século XX; e o da campanha antimanicomial, que tem seu marco inicial no Movimento de Trabalhadores de Saúde Mental, em 1978. Entre um movimento e outro, os trabalhos desenvolvidos nas décadas de 1930, 40 e 50 do século XX ficam esquecidos e os autores desse período passam a ser designados pioneiros, instaurando uma variante da busca do mito das origens.

Descritores: Nise da Silveira. Saúde mental. Psicologia. História da Psicologia.

$\mathrm{N}$ ise Magalhães da Silveira nasceu no dia 15 de fevereiro de 1905, numa casa da rua Boa Vista, na cidade de Maceió, Alagoas. A filha de Faustino Magalhães da Silveira e de Maria Lydia da Silveira mudar-se-ia para a rua do Sol e, posteriormente, para a rua do Frechal de Cima - atual rua Faustino da Silveira, em homenagem ao antigo morador (cf. Sant'ana, 2001).

O período do nascimento de Nise da Silveira é de grandes transformações nas idéias que sustentavam o mundo ocidental. As assombrosas des-

1 Docente da Universidade Federal de São João Del Rei. Endereço eletrônico: wmelojr@ gmail.com 


\section{Walter Melo}

cobertas efetuadas pela teoria da relatividade de Einstein e pela psicanálise de Freud modificaram por completo tanto o mundo físico quanto o mundo psíquico. As linhas que sustentavam o mundo começam a ceder, e o eixo sofre enormes modificações. As certezas tornam-se relativas e a razão é o que menos contribui nos comportamentos e tomadas de decisão dos indivíduos, que passam a se apresentar divididos, abrindo-se as portas para as insondáveis e instigantes pesquisas acerca do inconsciente. Os espaços do mundo externo e interno sofrem alterações que, se forem levadas em consideração, criam inúmeras interrogações: Será que todos os que circulam pela rua Boa Vista passam pela mesma rua? Quantas casas foram habitadas nas três casas de infância de Nise da Silveira? Quantas cidades existem na cidade de Maceió?

Se pensarmos o espaço de maneira estritamente geográfica, a resposta para essas indagações apresenta-se de modo simples: a rua, a casa e a cidade são as mesmas para todos. Diversos estudos, no entanto, apontam-nos para as alterações espaciais que acontecem quando levamos em consideração o espaço vivido, podendo ocorrer estreitamentos angustiantes, alargamentos paralisantes, perda de perspectiva, subversões de toda ordem, que evidenciam, além dos aspectos psicológicos inerentes a essas mudanças, fatores de ordem econômica, de cunho social e aspectos políticos.

Enquanto algumas pessoas mantêm a casa fechada para quem não é familiar, a casa da família Magalhães da Silveira estava sempre aberta aos amigos e convidados que, sentados à varanda ou deitados em redes, se refrescavam com a brisa da tarde e, na hora das refeições, eram fartamente servidos. Nesse ambiente acolhedor, os pais de Nise da Silveira recebiam os artistas que se apresentavam para a platéia alagoana e os intelectuais que passavam pela cidade (cf. Sant'ana, 2001). Essa casa mostra-se como um local ameno, com fartura de alimentos, de alegria, de respeito e de afeto, tornando-se, anos mais tarde, para a idosa Nise da Silveira, numa casa onírica, misto de imaginação e memória, fazendo-a relembrar os versos de Mélancolie de Milosz': "Minha mãe, é em ti que penso, oh! Casa” (Silveira, citado por Kummer, 2004, p. 105).

Na casa de infância de Nise da Silveira ocorriam saraus comandados por Maria Lydia, exímia pianista, que, na futura avaliação da filha, beirava a

2 Este trecho aparece citado por Gaston Bachelard com pequenas alterações: "Eu digo: Mãe. Mas é em ti que penso, ó Casa” (Bachelard, 1990, p. 94). 
genialidade (cf. Gullar, 1996), enquanto Faustino, professor de matemática, recebia alunos como Aurélio Buarque de Holanda e Arthur Ramos que, posteriormente, alcançariam notoriedade. A casa da família Magalhães da Silveira era comparada com os mais requintados salões do Rio de Janeiro: "O salão de Faustino - freqüentado pelo que havia de mais destacado e elegante em nossa velha cidade, e no qual ouvia-se música, cantava-se e declamava-se podia ser comparado, guardadas as proporções, com o de D. Laurinda Santos Lobo" (Lima Junior, 1976, p. 55).

Nesse clima festivo e de efervescência cultural, Nise da Silveira estava em contato, desde muito jovem, com músicos, intelectuais, poetas, atores, etc. A inauguração do Theatro Politheama em Maceió intensificou a vida cultural na cidade. Após os espetáculos, os atores seguiam para a casa de Faustino e Maria Lydia. No dia 15 de fevereiro de 1909, por exemplo, numa festa em comemoração ao aniversário de Faustino e de sua filha Nise, Maria Lydia tocou músicas de Liszt e de Wagner e, em seguida, diversos outros artistas se apresentaram.

Durante os saraus eram recitadas poesias em português ou em outras línguas. Quando as estrofes do poema $O$ Livro e a América, de Castro Alves, eram declamadas, causavam grande admiração na pequena Nise. $\mathrm{O}$ trecho em que Jeová conclama - "Vai, Colombo, abre a cortina / Da minha eterna oficina... / Tira a América de lá" - exacerbava a imaginação da menina, que se espantava com o tamanho da (im)possível cortina.

A menina se admirava, pois não fazia diferença entre espaço geográfico e espaço poético. Dessa maneira, o pensamento tende para a concretude e cria, paradoxalmente, uma cena de pura imaginação: uma cortina imensa que cobre toda a América. Nesse caso, tratar-se-ia realmente de um ato de descoberta, pois as terras estavam escondidas. Mas como não enxergar tamanha cortina?

Da mesma maneira que a menina se espantava por encontrar o mundo todo pronto numa poesia, necessitando apenas ser descoberto por trás de um imenso pano, muitos vão proceder desse modo com a própria Nise da Silveira. No afã de explicar como uma pessoa pôde fazer tanto - e ser tão libertária - vivendo num mundo que prega a exclusão, procuram-se, muitas vezes, explicações para a origem do gênio libertador em cenas da infância. 


\section{Walter Melo}

Nessa busca pelas origens do tema da libertária, os (per)seguidores de Nise da Silveira passam a repetir histórias contadas pela própria Nise da Silveira em entrevistas e reuniões de estudo. A memória social desenvolvida pela trajetória de Nise da Silveira na cultura brasileira passa a ser relembrada em textos, seminários e homenagens que lhe prestam. Em uma das histórias que contou em seus últimos anos de vida, ela narra que, quando contava quatro anos de idade, se deparou com uma galinha pedrês amarrada, esperando para ser morta e servida no almoço; a criança, vendo uma lágrima correr dos olhos tristes do animal, soltou um estridente grito; Faustino veio correndo ver o que acontecia e, temendo que a filha sofresse com a morte da galinha, ordenou que se modificasse o cardápio; a galinha liberta morreu anos depois, de velhice. Essa história - contada em conjunto com outra, segundo a qual a menina Nise, alguns anos depois, impediu um homem de chicotear um burrico que havia empacado em frente de sua casa -, sugere a presença do espírito libertário de Nise da Silveira desde a mais tenra idade.

Esse procedimento faz de Nise da Silveira uma predestinada e um ser a-histórico, transformando o tempo num ciclo que se fecha e se explica por si mesmo, ou seja, trata-se de um tempo mítico. A predestinação que se atribui a Nise da Silveira se dá após os fatos já terem ocorrido. Mito e história não necessariamente se excluem, ao contrário, se alimentam de maneira mútua. Dessa forma, as mudanças que Nise da Silveira empreendeu no campo da saúde mental são explicadas, muitas vezes, por características pessoais que já se encontrariam presentes em acontecimentos de sua infância.

É fato, por exemplo, que as principais características da casa de infância de Nise da Silveira, que se constituía como um ponto de encontro para se estimular uma produção cultural, foram levadas adiante, estando presentes também na casa de Nise quando, já adulta, foi morar no Rio de Janeiro com seu marido Mário Magalhães da Silveira (cf. Moreira, 2001). Mas será que existe alguma ligação de causa e efeito entre o clima de liberdade em casa e as mudanças que Nise da Silveira empreendeu na psiquiatria? Parece-nos que não. Cabe-nos, então, criar possibilidades de diálogo com as inúmeras idéias que, ao buscar o mito de gênese da libertadora em acontecimentos da infância, produzem explicações desprovidas de qualquer argumento histórico, além de apresentar vários fatos para possibilitar que a história possua a incumbência de demonstrar a veracidade do mito. 
Essas histórias foram contadas por Nise da Silveira, que, consagrada pelos grupos que dela se aproximaram, desempenha a capacidade de corroborar seu discurso através da simples enunciação do conteúdo narrado. Dessa forma, as histórias passam a ser relembradas em diversas ocasiões, tornandose ela própria a enunciadora de seu mito. A interrogação nesse caso é inexistente, pois nunca ouvimos ninguém se perguntar se, na história da galinha pedrês, é realmente possível a lágrima correr. Caso alguém venha a se questionar sobre esse fato, a resposta dada será que isso pouco importa, mantendo o mito intacto - pois as histórias dos heróis não começam, por exemplo, com a fecundação por chuva de ouro? Constituindo-se quase sempre como um duplo nascimento? Sendo eles dotados de poderes especiais? Destacando-se ora pela força incomensurável, ora pela sabedoria incomum?

\section{Liberdade: apelido e nome}

Como podemos ver, a busca da origem do mito da liberdade na trajetória de Nise da Silveira aparece em histórias da infância, na relação com os pais, na porta da casa aberta para as visitas etc. Nessa procura, Nise da Silveira vai recuando no tempo até transcender o mito familiar, alcançando, através de seu avô paterno, a figura de Zumbi. O pai de Faustino, não agüentando as mazelas impostas por sua esposa, Dona Henriqueta, a "terrível matriarca" (cf. Silveira citado por Gullar, 1996), se refugiou numa casa comercial que também lhe servia de residência. Essa casa ficava na cidade de União dos Palmares, fazendo com que a liberdade alcançada pelo avô fosse se juntar ao espírito libertário de Zumbi - o que passou a ser, para Nise da Silveira, a imagem que idealizou durante a infância.

Outros dois aspectos que enfatizam o mito da liberdade podem ser encontrados no apelido Caralâmpia e no nome Nise. O primeiro está ligado com a liberdade da imaginação, enquanto o segundo foi retirado dos sonetos de Cláudio Manuel da Costa, um dos idealizadores do movimento de Insurreição Mineira. 


\section{Walter Melo}

Faustino lecionava e, dentre os vários nomes que se encontravam na pauta de aula, a pequena Nise se encantou com o nome de José Caralâmpio 3 . No dia seguinte seriam ministradas provas, e Nise pediu ao pai para não reprovar o rapaz com nome tão bonito. Dias depois, Faustino chegou com o resultado da prova e mostrou para a filha que o rapaz com o belo nome não havia se saído bem nos exames. A partir de então, Faustino passou a chamar a filha pelo apelido de Caralâmpia ${ }^{4}$. $\mathrm{O}$ apelido estava diretamente vinculado à capacidade imaginativa de Nise da Silveira - sempre que o mundo se tornava agradável ou aterrador, ela recorria ao mundo de Caralâmpia. Essa mistura de diversão e proteção foi utilizada por toda a sua vida, tanto para criar cumplicidade (como nas conversas que travava com Graciliano Ramos na livraria José Olympio), quanto para tranqüilizá-la em momentos difíceis, como no dia em que, já idosa e presa a uma cadeira de rodas, tinha que subir uma escadaria na Fundição Progresso. Receosa, fechou os olhos e, de maneira divertida e tranqüila, se imaginou como uma sinhazinha passeando de liteira.

A origem da palavra caralâmpia possui sua base em dois radicais: ara, que significa felicidade, e lampos, designando brilho. Caralâmpia significa, portanto, brilho de felicidade.

O nome Nise, por sua vez, aparece diretamente vinculado ao arcadismo de Cláudio Manuel da Costa. Os gregos criaram a Arcádia como uma utopia na qual se conserva "a saudade de um mundo inocente, isento de ambições terrenas, ingênuo, tranqüilo" (Lopes, 1975, p. 8). Dessa maneira, a poesia pastoril é a que retrata da melhor maneira o mundo ameno que se deseja tornar realidade. A Escola Mineira, ligada nas artes ao arcadismo, encontra-se intimamente relacionada ao "projeto de libertação nacional" (Lopes, 1997, p. 90), tendo como principais mentores Alvarenga, Tomás Antônio Gonzaga e o próprio Cláudio Manuel da Costa.

3 De acordo com Nise da Silveira, o rapaz com o nome de José Caralâmpio se tornou, anos mais tarde, um eminente político alagoano. Dídimo Otto Kummer sugere a possibilidade de se tratar de José Caralâmpio de Mendonça Braga - "advogado, político, jornalista e poeta dos bons” (Kummer, 2004, p. 41) - que, em 1933, substituiu Luiz da Silveira, tio paterno de Nise da Silveira, no Jornal de Alagoas.

4 Graciliano Ramos se inspirou no poder imaginativo de Nise da Silveira para escrever o conto infantil A Terra dos Meninos Pelados, cuja personagem principal é a Princesa Caralâmpia. 
O movimento de Insurreição Mineira queria provocar um corte republicano, libertando o Brasil do colonialismo. A base das concepções desse grupo mineiro encontra-se no iluminismo. Do lema francês que pregava liberdade, igualdade e fraternidade, a ênfase mineira recaiu na liberdade, ficando impressa na bandeira do estado de Minas Gerais a inscrição libertas quae sera tamen (liberdade ainda que tardia). A sugestão de Cláudio Manuel da Costa era mais radical, pois não abria a possibilidade de a liberdade ser conquistada num momento futuro, exigindo-a para o presente: aut libertas aut nihil (ou a liberdade ou nada). A apropriação dessa idéia pela história oficial é evidente, dado que o próprio colonizador é tido como o que liberta o país do colonialismo e, antes que um aventureiro lance mão, profere o grito independência ou morte na beira de um riacho.

A poesia de Cláudio Manuel da Costa, estreitamente relacionada ao ideal libertário, é, de maneira paradoxal, considerada como um modo de exaltar as terras portuguesas. Essa idéia encontra-se presente desde a publicação de suas obras completas, em 1903, por João Ribeiro. Essa publicação retirou o poeta Cláudio do ostracismo, mas acabou por divulgar a idéia despropositada de exclusivo amor pelas terras colonizadoras. Logo ele, Cláudio, tão radical em suas propostas de libertação? Essa idéia encontra-se ligada ao fato de Cláudio ser, dentre os poetas do grupo mineiro, "o mais preso aos modelos arcádicos" (Bandeira, s.d., p. 53), ilustrando a paisagem brasileira com pastores, ovelhas, vinhedos e azeites, típicos do território europeu.

Ocorre aí uma confusão entre espaço geográfico e espaço poético. Os temas literários não pretendem delimitar nem a paisagem de Minas Gerais nem a de alguma região de Portugal. O espaço literário transcende as montanhas e os rios como limites geográficos naturais, possibilitando ao poeta mineiro metamorfosear paisagens, abrindo caminho para a criação de uma identidade nacional a partir de uma topologia mítica: "Tanto quanto nós, Cláudio e os poetas todos de seu tempo sabiam que não existia em Minas a máquina toda da paisagem arcádica que eles pintam em seus poemas - como nunca existira, de fato, tal parafernália, em nenhum rincão do mundo, fora das utopias da arte" (Lopes, 1997, p. 101).

Cláudio é considerado um dos maiores sonetistas da língua portuguesa, sendo avaliado por Manuel Bandeira, dentre os poetas do grupo mineiro, 


\section{Walter Melo}

como "o mais correto na metrificação e na linguagem" (Bandeira, s.d., p. 53). Os sonetos, em número de cem, podem ser lidos e compreendidos tanto de maneira separada quanto "como partes constituintes de um poema maior" (Lopes, 1997, p. 110). Essa leitura em conjunto é possível pelo fato de todos os poemas se estruturarem a partir do tema geral da falta, que se apresenta de duas maneiras: o objeto amado ora é inatingido, ora é perdido. Para tal, o poeta se vale das figuras do pastor e da pastora. O pastor Fido apresenta-se como o fiel amante de uma mulher inconstante ou indiferente, e, no Soneto XXII, demonstra toda a sua desventura. $\mathrm{O}$ amor aparece na poesia de Cláudio, a exemplo de outros autores, como o sentimento que vivifica, e sua perda é igualada à desumanização e à morte: Fido, sentado na pedra, se congela numa estátua de dor.

A busca da amada está presente de maneira direta em quase todos os sonetos e, naqueles em que esse tema não é explícito, a melancolia do texto e a idéia de um poema maior mantêm a continuidade da falta. Nessa busca, o pastor canta o nome de várias mulheres, sendo Nise sua "figura predileta" (Lopes, 1975, p. 21). O chamado "ciclo de Nise" (p. 30), composto por 16 sonetos, sendo 12 em português e 4 em italiano, apresenta a mulher amada que se torna a presença mais marcante dos sonetos. Assim como Dante exaltou Beatriz, Petrarca cantou Laura, Camões teve Natércia como amada e Tomás Antônio Gonzaga tornou-se o Dirceu de sua Marília, o arcadismo de Cláudio o transformou n'o lírico de Nise.

Em Hesíodo, aparece o nome Nesea; em Camões, existe uma ninfa marinha com o nome Nise. Alguns consideram que Nise provém da combinação das letras do nome Inês, que, por sua vez, possui sua origem em Agnes, significando a pureza. No entanto, nenhum desses nomes serve como referência para a Nise pastoril de Cláudio Manuel da Costa. A mulher amada por Cláudio, geralmente nomeada por Nise, apresenta-se como a "desejada inacessível" (Lopes, 1975, p. 22) e possui como provável imagem prototípica a Nise cantada por Virgílio e que não cede aos apelos de Damon.

O jogo de espelhos provocado pela inacessibilidade da amada que se faz presente na lembrança cria um duplo sofrimento, pois, ausente no mundo externo e presente no mundo interno, Nise inscreve o amor impossível, configurando a falta: "É uma temática em que Cláudio não tem competidores em nossa língua. A tomada de consciência da Falta por meio da auto-observação 
do estrago causado pelo sentimento da perda" (Lopes, 1997, p. 127). Dentre todos os sonetos de Cláudio Manuel da Costa, o mais conhecido, que faz parte do ciclo de Nise, é o de número XIII, "que é o verdadeiro dos poemas que tratam do delírio amoroso" (p. 126):

Nise? Nise? Onde estás? Aonde espera

Achar-te uma alma que por ti suspira,

Se quanto a vista dilata, e gira,

Tanto mais de encontrar-te desespera!

Ah! se ao menos teu nome ouvir pudera

Entre esta aura suave, que respira!

Nise, cuido que diz; mas é mentira.

Nise, cuidei que ouvia; e tal não era.

Grutas, troncos, penhascos de espessura, Se o meu bem, se a minha alma em vós se esconde,

Mostrai, mostrai-me a sua formosura.

Nem ao menos o eco me responde!

Ah! como é certa a minha desventura!

Nise? Nise? Onde estás? Aonde? Aonde? ${ }^{5}$

O pastor Fido mostra-se sempre fiel ao amor de Nise, que, com total liberdade, se apresenta como o desejo que se torna difícil de alcançar. Levando em consideração que a poesia do grupo mineiro é a representação artística dos ideais libertários que não se fizeram possíveis, não é improvável que Nise, "o mais querido nome de mulher" (Lopes, 1975, p. 21) presente nos sonetos de Cláudio, seja a configuração da liberdade, desejada e amada, mas que ficou reservada para um período tardio.

5 De acordo com Sérgio Buarque de Holanda, em crônica do dia 4 de outubro de 1953 no Diário Carioca, a última estrofe deste soneto possui referência no verso inicial do Endimião de Metastasio: "Nice, Nice, che fai? Non odi come..." (cf. Holanda, 1996). 


\section{Walter Melo}

No momento em que Nise da Silveira divulga que seu nome foi escolhido por seus pais a partir das poesias de Cláudio Manuel da Costa, instaura a busca das origens para o caráter libertário de seu trabalho no campo da saúde mental.

\section{A busca das origens}

O campo de estudo da constituição dos saberes psicológicos, mais especificamente da história da psiquiatria no Brasil, abrange, principalmente, dois períodos: o da campanha pró-manicomial, de construção/institucionalização do asilo - que parte da instauração da Sociedade de Medicina e Cirurgia do Rio de Janeiro, em 1829, indo até as primeiras décadas do século XX; e o da campanha antimanicomial, ou seja, da chamada reforma psiquiátrica brasileira, que tem seu marco inicial no Movimento de Trabalhadores de Saúde Mental, em 1978, e se estende até os dias de hoje. Nesse largo espectro temporal, algumas décadas ficam esquecidas, sendo que os autores que produzem nas décadas de 1930, 40 e 50 do século XX passam a ser tratados como ícones, negligenciando-se os caminhos de embates nos quais suas obras foram construídas e as repercussões que tiveram.

Uma autora comumente tratada como ícone é Nise da Silveira. Desde a década de 1930, seu nome passou a circular como exemplo de compromisso ético. A lembrança do nome de Nise da Silveira freqüentemente vem associada ao pioneirismo na humanização do asilo e nas idéias da reforma psiquiátrica. A ênfase na idéia de pioneirismo sugere uma identidade entre práticas e saberes díspares. É como se os trabalhadores de saúde mental contemporâneos dissessem: "O importante trabalho que fazemos atualmente já era feito há muito tempo por Nise da Silveira, mesmo que ela não soubesse disso". Estranha forma de conduzir a história de maneira a-histórica.

Observamos, pois, um sistema acrônico, no qual o pioneiro seria o desbravador que alcançou um conhecimento que elaboramos posteriormente. Nesse "especialismo acrítico" (Rodrigues, 1999, p. 115), inicia-se o discurso através das práticas atuais com o objetivo de retornar às origens. Dessa maneira, temos o seguinte esquema: as práticas hegemônicas da contemporaneidade são naturalizadas; as práticas contestatórias são excluídas do campo do saber; 
o passado é visto como reservatório de santos e/ou heróis; e, finalmente, há um retorno às práticas atuais, consideradas como destino inevitável.

Quando se denomina uma pessoa como pioneira, pretende-se prestar uma homenagem. Contudo, se analisamos detidamente essa idéia, percebemos que o centro não se encontra na pessoa a ser homenageada, mas sim na que faz a homenagem. Cria-se, dessa forma, uma identificação entre práticas totalmente diversas, na qual se subentende que a história se desenrola de maneira linear e numa perspectiva evolucionista. $\mathrm{O}$ auge de um modelo de trabalho se encontra, nesse tipo de pensamento, no presente. Os trabalhadores de um determinado campo - no caso, o da saúde mental -, de maneira fulgurante, iluminam seus próprios umbigos. Temos, assim, a criação de um saber liso, uniformizado e narcisista, que, partindo das práticas atuais, tenta encontrar suas origens. A noção de pioneiro é uma das manifestações do mito da origem, da criação de um momento inicial, que serve para excluir qualquer tipo de prática divergente com a finalidade de criar a história dos grandes feitos.

Nesse sentido, a escrita histórica é processada de maneira reificadora. Por exemplo, na tentativa de estabelecer A história da psiquiatria no Brasil, estamos baseados no pressuposto de que o tempo se desenrola num continuиm que se manifesta de diversas maneiras. A sucessão de fatos tende a estabelecer uma continuidade evolutiva entre um momento inicial e um presente luminoso. O compromisso, dessa maneira, é criar uma síntese que se pauta pela constância, pela unidade e pela harmonia, ou seja, a partir de critérios que formam a ideologia para uma história totalizante (cf. Neves, 1988).

A escrita histórica pode ser efetuada como uma tentativa de marcar rupturas, mas, a exemplo do ato de estipular A história através de nomes e datas que se desenrolam de maneira contínua no tempo, acaba por criar semelhanças entre práticas díspares. Como foi observado, entre a campanha prómanicomial e a campanha antimanicomial, um longo período intermediário ficou intocado. De maneira curiosa, estabelece-se uma identidade entre esse período esquecido pelos historiadores e o atual movimento de reforma psiquiátrica.

No caso de Nise da Silveira, que iniciou seu trabalho à frente da Seção de Terapêutica Ocupacional no hospital de Engenho de Dentro em 1944, tendo depois fundado o Museu de Imagens do Inconsciente em 1952 e a Casa 


\section{Walter Melo}

das Palmeiras em 1956, a noção de pioneira aparece de maneira explícita ou subentendida.

Em dois textos de Ana Pitta, temos Nise da Silveira - ao lado de Ulysses Pernambucano, Osório Cesar e Luiz Cerqueira - como precursores de um "enquadre ético de não abandono" (Pitta, 1994, p. 153) que encontraria práticas semelhantes nos dias de hoje, "atualizando no país uma rede histórica" (Pitta, 1996, p. 25) ligada aos pioneiros.

Benílton Bezerra, por sua vez, aponta Nise da Silveira, juntamente com Hélio Pelegrino, como exemplo de intelectual para quem a incessante busca da verdade "encontra-se a serviço da liberdade e da solidariedade" (Bezerra, 1992, p. 37) e, em outro texto, destaca o trabalho desenvolvido no Museu de Imagens do Inconsciente como uma das raras experiências anteriores ao Movimento de Trabalhadores em Saúde Mental que tentavam quebrar o poder hegemônico do sistema asilar sem, no entanto, possuir "uma perspectiva de transformação global do sistema" (Bezerra, 1994, p. 174).

Nesses exemplos, temos a busca das origens sintetizada na figura do pioneiro, tanto para se atualizar um sistema de valores com a finalidade de estipular o que pode e o que não pode ser utilizado como tratamento dos doentes mentais (enquadre ético), quanto na busca por uma sistematização teórica que se encontre a serviço dos ideais de liberdade e solidariedade, funcionando a teoria como uma espécie de ferramenta (enquadre pragmático), mas que, apesar de configurar um importante núcleo de resistência e de transformação, não consegue alcançar uma abrangência maior.

Outra noção apresentada e que se encontra estreitamente relacionada com as idéias de pioneiro e de busca das origens é a de ruptura épica (cf. Pitta, 1994). O modelo centrado na criação de grandes hospitais psiquiátricos, que possuem poucos técnicos para cuidarem de muitos internos, é substituído por Nise da Silveira, dado que, ao criar a Casa das Palmeiras, em 1956, coloca de cabeça para baixo a lógica manicomial. A Casa das Palmeiras é uma pequena instituição com as portas abertas, sendo proporcionalmente constituída por um grande número de técnicos tratando de poucos clientes. Dessa forma, invertese o vetor que apontava para a desumanização e a desintegração da personalidade, típica dos manicômios, e parte-se rumo à desinstitucionalização aliada a práticas de solidariedade. 
As mudanças atualmente em curso no campo da saúde mental são constituídas por duas vias: a substituição dos hospícios por novos dispositivos de tratamento e a homologação de leis que garantam juridicamente a continuidade dessas práticas. Nos dois casos, Nise da Silveira é tida como precursora. A ruptura épica ocorrida no momento da criação da Casa das Palmeiras é reatualizada, em 1987, quando Jairo Goldberg funda, em São Paulo, o Centro de Atenção Psicossocial (CAPS) Luiz Cerqueira. Ao contrário de Nise da Silveira, que não encontrou apoio da direção do hospital de Engenho de Dentro para a criação de uma instituição com as portas abertas, a criação do CAPS fez parte da política governamental e, para não perder essa oportunidade, Jairo Goldberg "brigava com os pedreiros para que tudo ficasse pronto" (Pitta, 1994, p. 164) antes do término do governo de Franco Montoro. É evidente a ênfase dada à inauguração das duas instituições e o tom grandiloquiente que descreve o surgimento da Casa das Palmeiras e do CAPS Luiz Cerqueira, pois o feito de romper com a exclusão estabelecida pelo modelo manicomial é considerado épico, ou seja, traz para o campo da saúde mental um ato digno dos heróis, dos desbravadores que, mesmo sem as condições financeiras adequadas, como no caso de Nise da Silveira, ou sem poder perder tempo, como na pressão sofrida por Jairo Goldberg, não se intimidam em face das dificuldades e tomam uma decisão que beneficia a coletividade. $O$ tema da busca das origens se expressa, dessa vez, em moldes institucionais, dado que a Casa das Palmeiras é, muitas vezes, considerada como precursora dos CAPS:

O trabalho iniciado por Nise da Silveira é responsável pela existência, hoje, de serviços de atendimento em saúde mental completamente diferentes do manicômio, onde a liberdade, a criatividade e a solidariedade entre pacientes e profissionais recupera seres humanos para o convívio social e a felicidade. A Casa das Palmeiras ... é pioneira no mundo no tratamento aberto. Os serviços de saúde criados a partir das suas descobertas - núcleos e centros de atenção psicossocial, ambulatórios de psiquiatria, ala psiquiátrica em hospitais gerais e o tratamento domiciliar - são hoje incorporados aos programas de saúde das organizações Mundial de Saúde e Pan-Americana de Saúde. (Delgado, 1998, p. 6)

Apresenta-se claramente nesse texto a vinculação da Casa das Palmeiras com os novos dispositivos institucionais criados pelo governo com a finalidade de substituir o modelo manicomial. Podemos encontrar relação semelhante no que diz respeito à chamada lei Paulo Delgado. Essa lei, aprovada 


\section{Walter Melo}

em 2001, dispõe sobre a diminuição dos leitos psiquiátricos e sua substituição gradual por novos dispositivos de tratamento, além de regulamentar a internação involuntária. A lei Paulo Delgado suscitou um amplo debate com toda a sociedade, quebrando barreiras econômicas, sociais e políticas para obter sua aprovação no Senado. Para tanto, o próprio Paulo Delgado afirma que se baseou em trabalhos anteriores e obteve apoio de diversas entidades e pessoas, como Nise da Silveira, "que começou a Reforma Psiquiátrica há mais de 40 anos na Casa das Palmeiras" (Delgado, 2001, p. 9). Quando Paulo Delgado elaborou o projeto de lei, em 1989, procurou imediatamente Nise da Silveira para obter a opinião da psiquiatra alagoana. Nise da Silveira sempre deu total apoio à iniciativa do deputado, apesar de considerar que a proposta poderia ser ainda mais restritiva em relação aos desmandos praticados nos manicômios: "Gostei muito do projeto de lei que propõe a substituição progressiva dos ma-

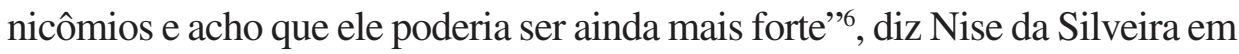
entrevista a Cláudio Cordovil ${ }^{7}$.

O governo levou 31 anos para adotar as medidas que Nise da Silveira empreendeu a partir da inauguração da Casa das Palmeiras. De 1987, ano de criação do primeiro CAPS, até os dias atuais, já foram criadas, em todo o território nacional, mais de 1000 instituições nesses moldes. Apesar de todas essas vinculações feitas entre a criação da Casa das Palmeiras como um serviço psiquiátrico com as portas abertas e a disseminação dos CAPS por todo o país, podemos afirmar que os CAPS, embora efetuem as mesmas diretrizes gerais, apresentam muitas diferenças entre si, pois "cada CAPS ... deve ter um projeto terapêutico do serviço, que leve em consideração as diferentes contribuições técnicas dos profissionais dos CAPS, as iniciativas de familiares e usuários e o território onde se situa, com sua identidade, sua cultura local e regional" (Ministério da Saúde, 2004, p. 16). O que não dizer, então, das diferenças existentes entre a abordagem empreendida por Nise da Silveira e o movimento de reforma psiquiátrica?

A primeira diferença que se observa é o fato de Nise da Silveira ter o seu nome associado ao estudo da psicologia junguiana, enquanto nos

\footnotetext{
6 De maneira, no mínimo, contraditória, Ferreira Gullar desaprova a chamada lei Paulo Delgado em livro dedicado a Nise da Silveira.

7 Jornal do Brasil, 1995.
} 
CAPS prevalece a abordagem psicanalítica aliada a um discurso de cunho social. A dupla imagem, de pioneira e de junguiana, cria uma figura paradoxal, ou melhor, ambivalente para o campo psiquiátrico. Essa ambivalência ocorre, principalmente, pelo fato de, no contexto da reforma, se tentar uma aproximação entre a prática da médica alagoana e a do grupo que participa dos eventos de luta antimanicomial, sugerindo uma correspondência de práticas e pensamentos que se dariam de maneira conjunta, ao mesmo tempo em que se cria um afastamento a partir da ação classificatória que faz de Nise da Silveira uma junguiana. A dicotomia entre mundo interno, típica das preocupações dos junguianos, de acordo com uma visão estereotipada, e mundo externo, no qual nos encontramos em meio a tantas necessidades sociais prementes, permanece inalterada e sustenta a ambivalência em relação aos métodos empregados pela médica alagoana.

O fato de Nise da Silveira ter introduzido o estudo sistemático da psicologia junguiana no Brasil reatualiza, no campo da saúde mental, a divergência entre Freud e Jung. Durante o I Encontro com Hélio Pellegrino, ocorrido no início da década de 1990 no Instituto de Psiquiatria da UFRJ, o filho do homenageado, Pedro Pellegrino, se pronunciou dizendo que havia um preconceito de cunho teórico em relação a Nise da Silveira, pelo fato de se tratar de uma junguiana em meio à maioria absoluta de psicanalistas atuantes no campo da saúde mental no Brasil. A coerção semântica que classifica Nise da Silveira tanto como pioneira quanto como junguiana possibilita um duplo jogo por parte dos profissionais engajados no movimento de reforma psiquiátrica: a aproximação entre os trabalhos de Nise da Silveira e da reforma psiquiátrica dar-se-ia pela contraposição de ambos os trabalhos em relação ao regime disciplinar, caracterizado, no campo psiquiátrico, pela prática manicomial; essa aproximação é feita, no entanto, pela manutenção da figura emblemática de Nise da Silveira e não por um amplo debate sobre suas idéias, afastadas exatamente pelo fato de serem classificadas como junguianas.

O poder classificatório não pode ser visto apenas em sua vertente negativa, que isola Nise da Silveira dos demais trabalhos empreendidos no campo da saúde mental. O fato de delimitar uma área de ação inusitada na psiquiatria brasileira possibilita, por outro lado, que se demarque um espaço de proteção que garante a continuidade da obra. A disseminação das idéias de Nise da Sil- 


\section{Walter Melo}

veira se dá em três vertentes: a difusão entre os (per)seguidores de seu trabalho, que têm acesso direto aos textos produzidos por ela, mas que perseguem uma leitura fundamentalista, fascinados que estão pela imagem da mestra; a propagação difusa entre os adeptos do movimento de reforma psiquiátrica, que nunca, ou quase nunca, debatem os textos de Nise da Silveira, mas tentam garantir uma aproximação através da criação de um ponto em comum, ou seja, a divergência em relação ao manicômio; e os antigos colaboradores que terminaram por se distanciar do grupo dos (per)seguidores do trabalho de Nise da Silveira, sem, no entanto, abandonar as suas concepções, propiciando releituras e apropriações criativas de seus conceitos e idéias.

Outra maneira de exercer o poder classificatório se dá através do procedimento histórico de criar modelos que se agrupam em formas gerais de pensamento, pautados em extremismos teóricos, matizados por práticas intermediárias, configurando a tensão, dentro do campo psiquiátrico moderno, entre três concepções de sujeito: biológica, social e psicológica. O sujeito biológico é concebido por profissionais que investigam as causas físicas e neuroquímicas da doença mental; o sujeito social é produzido pelo resgate da cidadania baseado na igualdade de direitos; e o sujeito psicológico é constituído a partir da afirmação da singularidade de cada um de nós.

Esse arranjo, essa verdadeira tipologia, está baseado numa concepção esquemática que estabelece idealizações "despidas de suas contradições" (Russo, 1997, p. 12). Dessa maneira, temos a indicação dos extremismos hegemônicos dentro do campo dos saberes psiquiátricos, caracterizando os três eixos básicos de atuação. $\mathrm{Na}$ descrição ficam faltando, porém, as orientações intermediárias, que podemos encontrar, de forma também esquemática, através do campo híbrido existente entre os eixos do sujeito psicológico e do sujeito social (cf. Leal, 2000). Esses enquadramentos, que ocorrem em esquemas teóricos ou temáticos abordados de forma linear ou, ainda, que se guiam pelos eixos principais e por suas orientações intermediárias, constituem as possibilidades lingüísticas de ordenação de práticas, experiências, singularidades e, mesmo, de disparidades.

As concepções apresentadas, apesar da proposta de contextualização, estabelecem, prioritariamente, tipologias. Dessa maneira, a análise de "paisagens intrincadas" (Rodrigues, 1999, p. 115) no campo da história dos saberes 
psicológicos vem ocorrendo dentro de modelos estanques que, apesar de reconhecerem que "há sobreposições, composições e alianças", propõem análises "despidas de suas contradições e matizes, como 'tipos ideais"” (Russo, 1997, p. 12). Pode-se ainda admitir que, ao se trabalhar com base em tipologias, ocorre "o risco de se perder a complexidade que caracteriza o campo" (Leal, 2000, p. 115). Esses modelos - tipificações idealizadas - são construídos com a intenção de se apreender num relance a maneira como se organiza o campo de atuação dos trabalhadores de saúde mental. Os modelos de modelos, no entanto, exercem um "teoricismo hipertrofiado" (Rodrigues, 1999, p. 115), dado que vão agrupando perspectivas teóricas a partir de seus conceitos e características de suas pesquisas.

Ao abandonar a utilização desses modelos de ordenação em linhas gerais, o conhecimento deixa de ser uma meta almejada e passa a ser o próprio caminho percorrido (cf. Neves, 1988). Passamos, então, a abordar a história, ao mesmo tempo, como uma prática e como um discurso. Dessa forma, apontando para a singularidade de um percurso e não para a maneira totalizante de sistematizar qualquer tipo de contribuição, podemos afirmar que os enunciados de Nise da Silveira "são históricos porque ligados a operações e definidos por funcionamentos. Também não se pode compreender o que dizem independentemente da prática de que resultam" (Certeau, 1982, p. 32). O entendimento da história como o relacionamento entre prática e discurso se faz como produção, ou seja, trata-se de uma prática que supera as dicotomias cultura/natureza e indivíduo/sociedade, e deixa de ser uma mera re(a)presentação de uma realidade pretérita.

Nise da Silveira lutou durante décadas contra métodos que considerava agressivos, típicos das práticas manicomiais, mas que ainda permanecem em uso, como o eletrochoque (principalmente nas instituições de ensino de psiquiatria), ou que voltaram a ser utilizados, como a lobotomia, que ressurgiu em hospitais psiquiátricos de Goiás. Esse retorno da prática da lobotomia encontra respaldo no mecanicismo que se manteve como base para as práticas psiquiátricas no momento em que se processou a mudança de tratamento a partir do advento das medicações psicotrópicas. Dessa forma, vemos configurar-se no campo da saúde mental uma alternância entre as práticas manicomiais e as antimanicomiais, ou seja, trata-se da instauração da psiquiatria alternativa. 


\section{Walter Melo}

Não era isso, de forma alguma, o que pretendia Nise da Silveira, que considerava urgente uma mudança completa nos métodos de tratamento empregados, pois a psiquiatria que alterna as atividades expressivas com a utilização do eletrochoque produz, no máximo, uma aceitação das diferenças nos moldes do liberalismo. As prementes mudanças necessitam, no entanto, da criação de práticas e teorias que sejam colocadas numa esfera totalmente diversa daquela em que os técnicos de saúde mental se encontravam, sob o risco de simplesmente se posicionarem contra e terem de conviver com o que se queria anular. Discordando da nomenclatura psiquiatria alternativa e da simples prática de negar a instituição manicomial, Nise da Silveira costumava citar o poema Ou Isto ou Aquilo de Cecília Meireles:

Ou se tem chuva ou não se tem sol, / ou se tem sol ou não se tem chuva!

Ou se calça a luva e não se põe o anel, / ou se põe o anel e não se calça a luva!

Quem sobe nos ares não fica no chão, / Quem fica no chão não sobe nos ares.

É uma grande pena que não se possa / estar ao mesmo tempo em dois lugares!

Ou guardo dinheiro e não compro doce, / ou compro doce e não guardo dinheiro.

Ou isto ou aquilo: ou isto ou aquilo... / e vivo escolhendo o dia inteiro!

Não sei se brinco, não sei se estudo, / se saio correndo ou fico tranqüilo.

Mas não consegui entender ainda / qual é melhor: se é isto ou aquilo!

O termo psiquiatria alternativa foi utilizado como título de um livro que Franco Basaglia lançou no Brasil. Assim como Nise da Silveira, Basaglia também elabora uma crítica sobre a inviabilidade de reorganizar a instituição psiquiátrica. O que pretendia, pois, era uma ruptura radical. O primeiro momento teria como base a negação da instituição psiquiátrica, que se daria através de um "processo de desativação do manicômio" (Basaglia, 1979, p. 8). Dessa forma, Franco Basaglia inicia sua proposta enfatizando o processo de desinstitucionalização, dado que, a partir dos levantamentos históricos e da simples observação do cotidiano manicomial, tem-se a caracterização de uma instituição da violência que deve ser negada. Em seguida, se propõe promover a superação da lógica manicomial e coloca-se numa posição de expectativa em relação ao futuro. A equipe italiana parte, então, da institui- 
ção negada para a instituição reinventada (cf. Rotelli, 1990), ou seja, para a criação de novas formas de lidar com a pessoa que se encontra em profundo sofrimento psíquico.

Basaglia abriu as portas das enfermarias, modificou a função exercida pelos auxiliares de enfermagem - que atuavam como carcereiros e passaram para a função de agentes de saúde -, promoveu amplos debates que implementaram a elaboração de leis e, principalmente, estabeleceu como método privilegiado a organização de assembléias dentro do hospital, exercitando, assim, o poder de contratualidade.

Seguindo esse tipo de pensamento, Benedetto Saraceno insere todos os atores envolvidos no campo da saúde mental num contexto de contratualidade, no qual o sujeito não é capacitado ou incapacitado, mas, sim, com maiores ou menores condições de estabelecer contratos. O enfoque adotado abandona a tentativa de se descobrir o que falta ou o que não funciona em determinado sujeito, incentivando-se o "poder de negociação" (Saraceno, 1996, p. 14). A contratualidade é vista como produtora de valor social, podendo se exercer em três cenários básicos: habitat, mercado e trabalho. Nesses cenários, serão estabelecidas trocas afetivas, sociais e econômicas.

A partir da noção de contratualidade, as variáveis que influenciam na melhora ou piora do quadro apresentado pelas pessoas que se tratam em serviços de saúde mental são de duas ordens de grandeza: o nível da afetividade, que supõe uma continuidade do tratamento, com bom vínculo entre profissional e paciente, interesse por parte do profissional, tempo gasto etc; e o nível político, ou seja, a organização da rede de saúde mental, na qual se leva em consideração o horário de funcionamento, o tipo de trabalho desenvolvido, a localização, o grau de satisfação com o atendimento prestado etc. Caso essas variáveis estejam a serviço do poder de contratualidade, consegue-se garantir "a construção da plena cidadania" (Saraceno, 1996, p. 17).

O exercício do poder de contratualidade, visando à construção da cidadania, forma o núcleo central do paradigma da reabilitação psicossocial. Abandonando o modelo de exclusão, institui-se a reabilitação como uma exigência ética calcada na solidariedade. A reabilitação não deve ser confundida com uma determinada técnica, pois se trata de "uma estratégia global" (Saraceno, 1996, p. 14), de uma postura que deve ser adotada por todos os atores 


\section{Walter Melo}

sociais envolvidos. Portanto, a reabilitação implica uma total modificação das políticas adotadas nos serviços psiquiátricos que ainda estão pautados no modelo hospitalocêntrico.

Está claro que ocorrem sobreposições entre os trabalhos de Basaglia e de Nise da Silveira, principalmente no que diz respeito à desmontagem do hospital psiquiátrico. De acordo com Nise da Silveira, a equipe italiana liderada por Franco Basaglia elaborou "o mais forte empreendimento de mutação na área da psiquiatria” (Silveira, 1992, p. 15). Entretanto, ocorrem pontos de divergência que interferem no modo de organizar os dispositivos substitutivos ao manicômio, pois, enquanto Nise da Silveira privilegia a expressão de si, os adeptos do movimento de reforma psiquiátrica conferem maior importância às noções de contratualidade, cidadania e reabilitação psicossocial. Essa discordância no foco de atuação foi apontada pela própria Nise da Silveira: "A proposta de Basaglia continua atualmente atraindo a maioria dos espíritos renovadores da área da psiquiatria, embora nos pareça ainda incompleta, por conceder pouca atenção aos fenômenos em desdobramento no espaço interno" (p. 15).

Os discursos de Franco Basaglia e de Nise da Silveira não podem ser homogeneizados e nem definitivamente separados em funções classificatórias diversas. Devemos, ao contrário, possibilitar debates que esclareçam os conceitos utilizados por Franco Basaglia e por Nise da Silveira. Esse diálogo não totalizante e não excludente pode ser extremamente benéfico para o atual momento de reformulação da prática psiquiátrica brasileira. Mas o que vemos acontecer é deificação desses instigantes autores, que, aos poucos, se transformam em imagens a cultuar, ou objetos de disputas pelos guardiões dos discursos oraculares, ou, ainda, simples artefatos comerciais.

O embate das idéias, longe de criar ações classificatórias que modelem instâncias redondas e tentem juntar, de modo perfeito, peças de quebra-cabeças diferentes, permite distanciarmo-nos das facilidades de enumerar um rol de atributos pelo qual se identificam os discursos psiquiátricos que objetivam a cidadania como típicos do liberalismo e os discursos calcados na expressão de si como característicos do romantismo. Nesse tipo de pensamento, os trabalhos desenvolvidos pelo movimento de reforma psiquiátrica seriam liberais, enquanto a proposta de Nise da Silveira se enquadraria no romantismo. Outro enquadre criado se dá a partir do paralelo entre as divisões pautadas pelas 
práticas sociais e as propostas clínicas, donde o movimento de reforma psiquiátrica seria classificado como de cunho social e Nise da Silveira privilegiaria uma abordagem clínica.

Essas funções classificatórias deixam de fora uma gama de práticas, discursos, valores, de ambos os lados, que não se encaixam no modelo proposto. Para que se possa lançar um olhar em direção ao refugo criado por essas classificações, devemos abandonar as coerções semânticas e, dessa maneira, abrir a possibilidade de leitura das seguintes frases de Nise da Silveira, escritas em 1966, principalmente no momento de implantação dos CAPS como dispositivos privilegiados de tratamento: "a reabilitação é focalizada em primeiro lugar e as terapêuticas tornam-se o seu instrumento"; "a meta de todo tratamento psiquiátrico não pode mais continuar sendo a remoção de sintomas, porém a recuperação do indivíduo para a comunidade"; e "o fio diretor do tratamento ocupacional na nossa seção é a reabilitação" (Silveira, 1966, p. 56). Ao ler cuidadosamente a obra de Nise da Silveira, fugimos das classificações e damos visibilidade à heterogeneidade de seu trabalho e ao caráter fecundo de suas práticas.

Melo, W. (2007). Maceió is a Mythical City: The myth of origin in Nise da Silveira. Psicologia USP, 18(1), 101-124.

\begin{abstract}
The field of mental health in Brazil covers two periods of time: the one involving the campaigns in favor of the insane asylums, from 1829 until the first decades of the twentieth century; and the antiasylum campaigns, which had their initial mark in the Movimento de Trabalhadores de Saúde Mental (Mental Health Workers' Movement) in 1978. Between one movement and another, studies developed in the 1930s, 1940s and 1950s were left forgotten and authors of this period are referred to as pioneers, establishing a variant in the search for the myth of origin. The present article discusses the myth of origin in Nise da Silveira's writings through the stories of her childhood, given the fact that her contributions in the field of mental health are seen, by several groups, as a fruit of her geniality and/or pioneering, finding explanations in the autobiographical reports, consecrated by her followers.
\end{abstract}

Index terms: Nise da Silveira. Mental health. Psychology. History of Psychology. 


\section{Walter Melo}

Melo, W. (2007). Maceió est une Ville Mythique: le mythe de l'origine chez Nise da Silveira. Psicologia USP, 18(1), 101-124

Résumé: L’histoire de la Santé Mentale au Brésil comprend deux périodes: celle de la campagne manicomiale, de 1829 jusqu'aux premières décennies du $\mathrm{XX}^{\mathrm{e}}$ siècle, et celle de la campagne antimanicomiale, qui a trouvé son premier souffle dans le Mouvement des Travailleurs de Santé Mentale en 1978. Les travaux développés pendant les années 30, 40 et 50 ont été oubliés et les chercheurs de cette période ont été désignés comme pionniers, car ils ont instauré une variante de la recherche sur le mythe de l'origine. Cet article aborde le mythe de l'origine chez Nise da Silveira à partir des histoires de son enfance, étant donné ses contributions dans le domaine de la Santé Mentale dès lors que certains groupes d'études arrivent a les comprendre comme fruits de sa génialité ou bien de son caractère pionnier, basés sur des rapports autobiografiques, ce que rabaisse la puissance de son oeuvre.

Mots clés: Nise da Silveira. Santé mentale. Psychologie. Histoire de la Psychologie.

\section{Referências}

Bachelard, G. (1990). A terra e os devaneios do repouso. São Paulo: Martins Fontes.

Bandeira, M. (s.d.). Apresentação da poesia brasileira. Rio de Janeiro: Ediouro.

Basaglia, F.(1979). A psiquiatria alternativa. São Paulo: Brasil Debates.

Bezerra, B. (1992). Da verdade à solidariedade: a psicose e os psicóticos. In B. Bezerra Júnior \& P. Amarante (Orgs.), Psiquiatria sem hospício: contribuições ao estudo da reforma psiquiátrica (pp. 31-37). Rio de Janeiro: Relume-Dumará.

Bezerra, B. (1994). De médico, de louco e de todo mundo um pouco: o campo psiquiátrico no Brasil dos anos oitenta. In R. Guimarães \& R. Tavares (Orgs.), Saúde e sociedade no Brasil: anos 80 (pp. 171-191). Rio de Janeiro: Relume-Dumará.

Certeau, M. de. (1982). A escrita da história. Rio de Janeiro: Forense.

Costa, C. M. da. (1997). Sonetos. Rio de Janeiro: Nova Fronteira.

Delgado, P. (1998, 22 de agosto). Senhora das mentes e da paz [Editorial]. Jornal de Brasília, p. 6.

Delgado, P. (2001). O desafio é deslocar recursos. Revista da Saúde, 2(2), 8-9. 


\section{Maceió é uma Cidade Mítica: o Mito da Origem em Nise da Silveira}

Gullar, F. (1996). Nise da Silveira: uma psiquiatra rebelde. Rio de Janeiro: RelumeDumará.

Holanda, S. B. de. (1996). De Cláudio ao cantor Cesáreo. In O espírito e a letra: estudos de crítica literária (1948-1959) (Vol. II, pp. 595-598). São Paulo: Companhia das Letras.

Kummer, D. O. (2004). Nise: abecedário de uma libertadora. Maceió: Catavento.

Leal, E. M. (2000). O campo da reforma psiquiátrica brasileira: noções de "sujeitos" e "mundo" presentes no discurso dos agentes do cuidado. Cadernos do IPUB: Antropologia e História dos Saberes Psicológicos, (18) 102-122.

Lima Júnior, F. (1976). Maceió de outrora. Maceió: Arquivo Público de Alagoas.

Lopes, E. (1997). Metamorfoses: a poesia de Cláudio Manuel da Costa. São Paulo: UNESP.

Lopes, H. (1975). Cláudio, o lírico de Nise. São Paulo: Fernando Pessoa.

Ministério da Saúde. (2004). Saúde mental no SUS: os Centros de Atenção Psicossocial. Brasília: Autor.

Moreira, M. (2001). Uma casa nordestina. Quaternio, (8), p. 144.

Neves, L. F. B. (1988). As máscaras da totalidade totalitária: memória e produção sociais. Rio de Janeiro: Forense-Universitária.

Pitta, A. (1994). Cuidado de psicótico. In J. Goldberg, Clínica da psicose: um projeto na rede pública (pp. 154-166). Rio de Janeiro: Te Corá.

Pitta, A. (1996). O que é reabilitação psicossocial no Brasil, hoje? In A. Pitta (Org.), Reabilitação psicossocial no Brasil (pp. 19-26). São Paulo: Hucitec.

Rodrigues, H. de B. C. (1999). Sobre as histórias das práticas grupais: explorações quanto a um intrincado problema. In A. M. Jacó-Vilela \& D. Mancebo, Psicologia social: abordagens sócio-históricas e desafios contemporâneos (pp. 111-165). Rio de Janeiro: EdUERJ.

Rotelli, F. (1990). A instituição inventada. In F. Nicácio. (Org.), Desinstitucionalização (pp. 89-99). São Paulo: HUCITEC.

Russo, J. (1997). Os três sujeitos da psiquiatria. Cadernos do IPUB: Noções de Pessoa e Institucionalização dos Saberes Psicológicos no Brasil, (8) 11-21.

Sant'ana, M. M. de. (2001). Nise da Silveira, a reinvenção da psiquiatria. Quaternio, (8), 207-217.

Saraceno, B. (1996). Reabilitação psicossocial: uma estratégia para a passagem do milênio. In A. Pitta (Org.), Reabilitação psicossocial no Brasil (pp. 13-18). São Paulo: HUCITEC.

Silveira, N. da. (1966). Teoria e prática da T.O. Rio de Janeiro: Casa das Palmeiras. 


\section{Walter Melo}

Silveira, N. da. (1992). O mundo das imagens. São Paulo: Ática.

Recebido em: 9/04/2007

Aceito em: 7/05/2007 